Test your Skill

3 minutes.

Use double-line spacing.

T8 - SI 1.42

\section{LESSON 56}

\section{Letter 27}

PAPER: A5.

TARGET TIME: 12 minutes.

Take a carbon copy of this reply to the letter in Lesson $\mathbf{5 3}$ and address a suitable envelope.

Letter 28

PAPER: A5.

TARGET TIME: 10 minutes.

This is a personal business letter.

Display 5

PAPER: A6 (148 x $105 \mathrm{~mm})$.

TARGET TIME: 10 minutes.

Type this notice.
Under a credit sales agreement ownership does not belong to the seller of the article but passes direct to the buyer who must repay the debt, again plus the interest being charged. The cheapest way of buying anything is to save up - and be paid the interest for doing so - and pay cash for goods. A straight cash purchase can often be made with good discount being given so that the wise buyer gains, receiving both interest and discount.

Ref. GC/SW To-day's date

Miss Shirley Westerholt, 29 Cricket Lane, Kidderminster, Worcs.

Dear Miss Westerholt, We thank you for your request for our Special offer Parcel. (Paragraph)

Owing to great demand this year, we regret that we have sold out of these parcels and cannot replace them at this late stage. If, however, you would be interested in selecting one or two lines from our catalogue, we should be only too pleased to supply them. A further order form is enclosed.

Yours faithfully, QUALITY CARDS. LIMITED

Graham Craddock Managing Director Enc.

Fron: 6 High Street. Norton, Bath. BA4 8No

To: The Square Deal Goraqe, 11 Beluidere Road, Bath. BA8 $18 R$ To-day's date. Deas Sirs, I was susprised to receise a bill for f37 for repair to my car in the post this morning. The repairs were supposed to be undertaken as part of a Warranty claim on my new car. (Paragast) Will you please check your necotds and cancel this bill. yours faithfully. Michael ward * Typist, please addrex the enelope.

T. P. Riley School

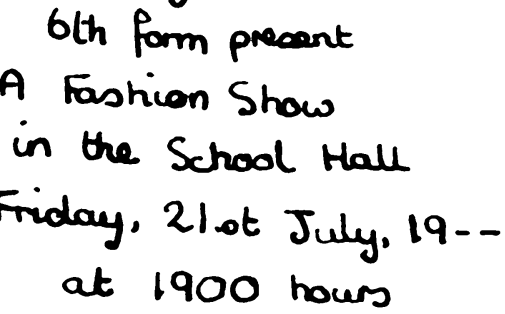

Ticket - Admit Ore 